\title{
BMJ Open Assessing the knowledge, perception and practices of physicians and pharmacists towards medication reconciliation in Kuwait governmental hospitals: a cross-sectional study
}

To cite: Lemay J, Bayoud T, Husain $\mathrm{H}$, et al. Assessing the knowledge, perception and practices of physicians and pharmacists towards medication reconciliation in Kuwait governmental hospitals: a crosssectional study. BMJ Open 2019;9:e027395. doi:10.1136/ bmjopen-2018-027395

- Pre-publicaton history and additional material is published online only. To view please visit the journal online (http://dx.doi. org/10.1136/bmjopen-2018027395).

Received 26 0ctober 2018 Revised 26 March 2019 Accepted 8 May 2019

Check for updates

(C) Author(s) (or their employer(s)) 2019. Re-use permitted under CC BY-NC. No commercial re-use. See rights and permissions. Published by BMJ.

${ }^{1}$ Faculty of Pharmacy, Department of Pharmacology \& Therapeutics, Kuwait University - Shuwaikh Campus, Shuwaikh, Kuwait

${ }^{2}$ Faculty of Pharmacy, Department of Pharmacy Practice, Kuwait University Shuwaikh Campus, Shuwaikh, Kuwait

${ }^{3}$ Dasman Diabetes Institute, Kuwait City, Kuwait

Correspondence to Dr. Jacinthe Lemay; j.lemay@hsc.edu.kw

\section{ABSTRACT}

Objectives To assess the knowledge, perception and practices towards medication reconciliation (MedRec) and its related institutional policies among physicians and pharmacists in governmental hospitals in Kuwait and identifying potential obstacles that prevent the successful implementation of MedRec.

Design A descriptive, cross-sectional study.

Setting Six governmental hospitals across Kuwait in January-May 2017.

Participants 351 physicians and 214 pharmacists. Brief intervention A self-administered questionnaire distributed to the participants.

Main outcome measures Knowledge, perception, attitudes and practices of hospital physicians and pharmacists towards MedRec, and major barriers to implementing a MedRec process in their institution/ department.

Results Of the 739 questionnaires distributed, 565 were completed (351 physicians and 214 pharmacists), giving a response rate of $76.5 \%$. Results showed that most participants were familiar with the term MedRec $(n=419$; $75.2 \%$ ) with significantly more pharmacists compared with physicians ( $n=171 ; 81.8 \%$ vs $n=248 ; 71.3 \% ; p=0.005)$. Most participants ( $\mathrm{n}=432 ; 80.0 \%)$ reported perceiving MedRec as a valuable process for patient safety. However, significantly more physicians compared with pharmacists were aware of a MedRec policy in their institution $(n=195 ; 55.9 \%$ vs $n=78 ; 37.9 \% ; p<0.001)$ and routinely asked patients about their current list of medication on arrival $(n=339 ; 96.6 \%$ vs $n=129 ; 61.1 \% ; p<0.001)$ and provided an updated list on discharge $(n=281 ; 80.1 \%$ vs $n=107 ; 52.0 \% ; p<0.001)$. These results are supported by the findings that participants perceived physicians as providers, mainly responsible for various steps of MedRec. Conclusions Overall, this study showed low awareness among physicians and pharmacists of hospital policy despite MedRec being perceived as valuable. Physicians were the providers most responsible and involved in MedRec, who may be driven by the policy putting them at core of the process. The current findings could pave the way for the expansion of the existing MedRec policies and processes in Kuwait to include pharmacists and improve patient safety.
Strengths and limitations of this study

- This is the first study to assess and compare the knowledge, perception and practices towards medication reconciliation (MedRec) between physicians and pharmacists working in hospitals in Kuwait.

- The study used a survey tool from an internationally recognised organisation-Institute for Safe Medication Practices.

- Since this study was conducted in public hospitals, the observations may not reflect the current situation in the private hospital and ambulatory care settings.

- This study focused on pharmacists and physicians, and as such, the current perspectives and practices of nurses regarding MedRec remain to be determined.

- The country where the participants obtained their degree was not captured, and as such, it was not possible to determine whether those who were trained in countries where MedRec policies are well established have better knowledge, attitudes and practices regarding MedRec.

\section{INTRODUCTION}

Medication reconciliation (MedRec) is a vital tool in clinical settings helping to reduce medication errors (MEs) and patient harm. ${ }^{1-3}$ MedRec is a collaborative process between healthcare providers (HCPs) and patients that involves obtaining the best possible medication history (BPMH) on patient admission and reconciling it with the physicians' medication orders for ensuring communication of complete and accurate medication information at every point of transition in care, whether admission, transfer or discharge. The intent is to identify, document and discuss discrepancies with the prescribing physician and make appropriate changes if needed to ensure patient safety. MEs occurring at points of transition in care can be caused 
by discrepancies whether intentional or non-intentional and may include omissions, duplications, dosing errors, different medication and so on, which may jeopardise patient safety and clinical outcomes. ${ }^{12}$

A major reason for implementing MedRec in hospital settings is to prevent errors in patient's medication regimen from admission to discharge, including points of care transfer within the hospital. Data showed that MEs occurred in up to $67 \%$ of patients admitted to hospital and were found to be clinically important in up to 59\% of cases. ${ }^{4}$ There is a large body of data demonstrating the clinical value of MedRec to reduce adverse drug events and MEs, thus improving patient safety and minimising patient harm. ${ }^{5-9}$ For example, the implementation of a multidisciplinary MedRec process was associated with significant decreases in the number of admission and discharge medication discrepancies and, serious or life threatening errors. ${ }^{10}$ In a controlled trial where patients were randomised to usual care or MedRec, a total of 327 discrepancies $(52.6 \%$ unintentional and $47.4 \%$ intentional) were identified among patients randomised to the MedRec group, with $64 \%$ of patients having one or more discrepancies at admission. ${ }^{6}$

For MedRec to effectively contribute towards patient safety, it must be an integral part of every institution's strategic planning and supported by institutional policies that describe processes and workflows, clearly defining responsibilities of all those involved. Furthermore, MedRec implementation must be aligned with accreditation Required Organizational Practices (ROP) and meet required tests for compliance. ROPs are defined by Accreditation Canada as fundamental practices that must be adapted by healthcare institutions to mitigate risk and ensure patient's safety. For instance, in order to comply with the MedRec ROP, institutions must develop and implement a MedRec policy and process to obtain and use a complete and accurate patient's medication information at each point of transition in care. An institution policy indicates leadership's commitment and provides guidance to MedRec implementation. The Institute for Healthcare Improvement, Joint Commission and the Institute for Safe Medication Practices (ISMP), among others, provide guidance for healthcare institutions to develop their policies and procedures and provide tools for implementation, education and monitoring as well as assistance in identifying gaps between current practice and best practice. ${ }^{1-3}$ The actual process and model of reconciling medicines may differ between various healthcare institutions, and for hospitalised patients, the process may be carried out numerous times when the patient is transferred from one point of care to another or during any point of hospital stay. It is critical to assign the leading responsibility of MedRec to key stakeholders within the organisation, to delegate organisational responsibilities, as well as role of each HCP involved in the process, and to identify and fulfil the ongoing training needs for effective implementation of the MedRec process. ${ }^{2}$
Data have shown that although HCPs appreciate the value and benefits of MedRec, there is inadequate knowledge and awareness of the MedRec process and policies, lack of clear understanding of the role of each HCP, inconsistencies across hospitals in the MedRec implementation process and underutilisation of pharmacists compared with physicians and nurses in MedRec. ${ }^{11-17}$ Given that pharmacists are trained as medication experts who may provide direct patient care, it seems counterintuitive that they are underused or not perceived as essential in the MedRec process. ${ }^{11} 1417$ Similarly, recent data from Middle Eastern countries showed low awareness of the MedRec concepts and policies among hospital pharmacists in Jordan and a lack of understanding and agreement on the roles and responsibilities of each profession among physicians, pharmacists and nurses working in a tertiary care academic hospital in Oman. ${ }^{11}{ }^{13}$ Recent data from Kuwait showed that hospital pharmacists support the implementation of MedRec in their institution but reported several barriers such as the absence of a policy promoting a role for pharmacists in the process. The Ministry of Health $(\mathrm{MoH})$ in Kuwait is working towards obtaining accreditation for their healthcare institutions, and MedRec is an ROP for accreditation. However, it remains to be determined whether HCPs in Kuwait have sufficient knowledge and understanding of the MedRec process, including the roles and responsibilities of each profession. To support the $\mathrm{MoH}$ endeavour, and given the paucity of data regarding MedRec in Kuwait, the objective of this study is to assess the knowledge, perception, attitudes and practices of hospital physicians and pharmacists towards MedRec and determine major barriers to implementing a MedRec process in their institution/ department.

\section{METHODS}

\section{Study design}

A descriptive, cross-sectional study was carried out from January to May 2017 among physicians and pharmacists working in secondary care MoH hospitals across Kuwait. These included Al-Amiri, Al-Sabah, Mubarak-Al-Kabeer, Al-Farwaniya, Al-Adan and Al-Jahra hospitals. Due to the nature of the nurses' training and their current roles and responsibilities, nurses were excluded from the study.

\section{Study tool}

The study tool was a self-administered questionnaire adapted from the ISMP survey and from a previously published study ${ }^{18} 19$ consisting of 29 questions to assess knowledge (three questions), perceptions (four questions), practices (nine questions), policies (four questions) and to collect demographic data (eight questions). The questionnaire also included one open-ended question to capture any additional comments from the participants and was distributed in English. A pilot study was conducted with 10 physicians and 10 pharmacists across two hospitals to test the content and face validity of the questionnaire. Minor format changes were made 
to improve clarity of some questions without changing their essence. The study questionnaire is presented in online supplementary appendix 1 . Pilot study data were excluded from the study results.

\section{Sample recruitment, data collection procedures and statistical analysis}

Only those who agreed to take part in the study by signing the informed consent were included. Pharmacy students distributed the questionnaires and followed up weekly during the data collection period. The sample size was calculated using Raosoft Sample Size Calculator. ${ }^{20}$ All 3477 physicians and 502 pharmacists working in $\mathrm{MoH}$ hospitals were considered eligible. However, to ensure the study objectives were met, pharmacists who work only in medicines storage or pharmacy labs were excluded, which provided an eligible pool of 445 pharmacists. Assuming a margin of error of $5 \%$ and a CI of $95 \%$, a sample of 347 physicians and 207 pharmacists was necessary. To achieve this goal, a larger number of questionnaires were distributed. Thus, questionnaires were distributed to 431 physicians and 308 pharmacists. A total of 351 and 214 questionnaires were completed and returned by physicians and pharmacists, respectively.

The data management and statistical analysis was carried out using the computer software 'Statistical Package for Social Sciences', SPSS V.25.0. The descriptive statistics have been presented as frequencies and percentages for categorical variables, and percentages are based on the actual participants' response to specific questions. The quantitative variables age and years of experience were ascertained for normal distribution assumption, applying the Kolmogorov-Smirnov test and being skewed are presented as: median, interquartile (IQ) and range. The Pearson $\chi^{2}$ or Fisher's exact test was applied to find any association or significant differences between categorical variables. The normal Z-test was used to compare the proportions between physicians and pharmacists using MedCalc software. MS Excel was used to prepare the figures. The median age, years of experience and value score for MedRec process were compared using non-parametric two-sample Kolmogorov-Smirnov or Mann-Whitney test. The two-tailed probability value ' $p$ ' $<0.05$ was considered statistically significant.

\section{Patient and public involvement}

No patients were involved in setting the research question or the outcome measures, nor were they involved in the design or conduct of the study. No patients were asked to advise on the interpretation or writing up of results. There are no plans to disseminate the results of the research to study participants.

\section{RESULTS}

\section{Demographics}

A total of 739 questionnaires were distributed (431 to physicians and 308 to pharmacists) and of those, 565 questionnaires were completed and returned (351 from physicians and 214 from pharmacists), giving an overall response rate of $76.5 \%$. The study sample consisted of $62.1 \%$ physicians $(351 / 565)$ and $37.9 \%$ pharmacists $(214 / 565)$. The sociodemographical characteristics of the participants are presented in table 1 . There were significantly more female pharmacists compared with physicians $(\mathrm{n}=123 / 208 ; 59.1 \%$ vs $\mathrm{n}=124 / 349 ; 35.5 \%$; $\mathrm{p}<0.001)$. The overall median age was 33 years, ranging between 23 years and 68 years and was not significantly different between physicians and pharmacists $(\mathrm{p}=0.456)$. Nationality-wise, both the groups represented almost equally. Both, Kuwaitis and non-Kuwaitis, had an average (median) 8 years of experience.

\section{Knowledge, training and perceptions about MedRec}

Most participants $(\mathrm{n}=419 ; 75.2 \%)$ reported being familiar with the term 'medication reconciliation', with significantly more pharmacists compared with physicians $(171 / 209 ; 81.8 \%$ vs $248 / 348 ; 71.3 \% ; \mathrm{p}=0.005)$ (table 2). Less than half of participants received training on MedRec during their university studies $(\mathrm{n}=224 / 557$; $40.2 \%)$ or in the work place $(n=240 / 557 ; 43.1 \%)$. However, in contrast to training in the workplace, significantly more pharmacists compared with physicians were trained at university $(\mathrm{n}=116 / 209 ; 55.5 \%$ vs $108 / 348$; $31.0 \%$; $\mathrm{p}<0.001$ ) (table 2).

When participants were asked to rate their perception of MedRec as a valuable process for patient safety ( $1=$ notvaluable to $5=$ =eryvaluable), the majority $(\mathrm{n}=432 / 540 ; 80.0 \%)$ perceived it as valuable or very valuable, with significantly more pharmacists perceiving it as very valuable $(\mathrm{n}=128 / 190 ; 67.4 \%$ vs $\mathrm{n}=186 / 350 ; 53.1 \%$; $\mathrm{p}<0.001)$. The overall mean score was $4.30( \pm 0.99 \mathrm{SD})$, significantly higher for pharmacist compared with physicians $(4.45 \pm 0.92$ vs $4.22 \pm 1.02 ; \mathrm{P}=0.004)$.

Participants were asked their perception of which healthcare professional was responsible for various steps involved in MedRec (figure 1); they could select more than one answer option for each step of the process. Overall, participants perceived that physicians are the main healthcare professionals responsible for various steps of the process, followed to a lesser extent by pharmacists and nurses. Significantly more physicians compared with pharmacists believed that physicians were responsible, and in contrast, significantly more pharmacists compared with physicians perceived that pharmacists were responsible.

\section{Participant knowledge of MedRec policies}

When asked about policies, almost half of the participants $(\mathrm{n}=273 / 555 ; 49.2 \%)$ agreed that there are policies about MedRec in their institutions, with significantly more physicians than pharmacists $(n=195 / 349 ; 55.9 \%$ vs $n=78 / 206$; $37.9 \% ; \mathrm{p}<0.001$ ) (table 3 ). The remaining mentioned either, 'no' (123/555; 22.2\%) or 'Don't know' (159/555; $28.6 \%$ ), significantly more among pharmacists than physicians $(\mathrm{n}=128 / 206 ; 62.1 \%$ vs $\mathrm{n}=154 / 349 ; 44.2 \%, \mathrm{p}<0.001)$ on the presence of MedRec policy. Of those $49.2 \%$ who 
Table 1 Sociodemographic characteristics of participants $(n=565)$

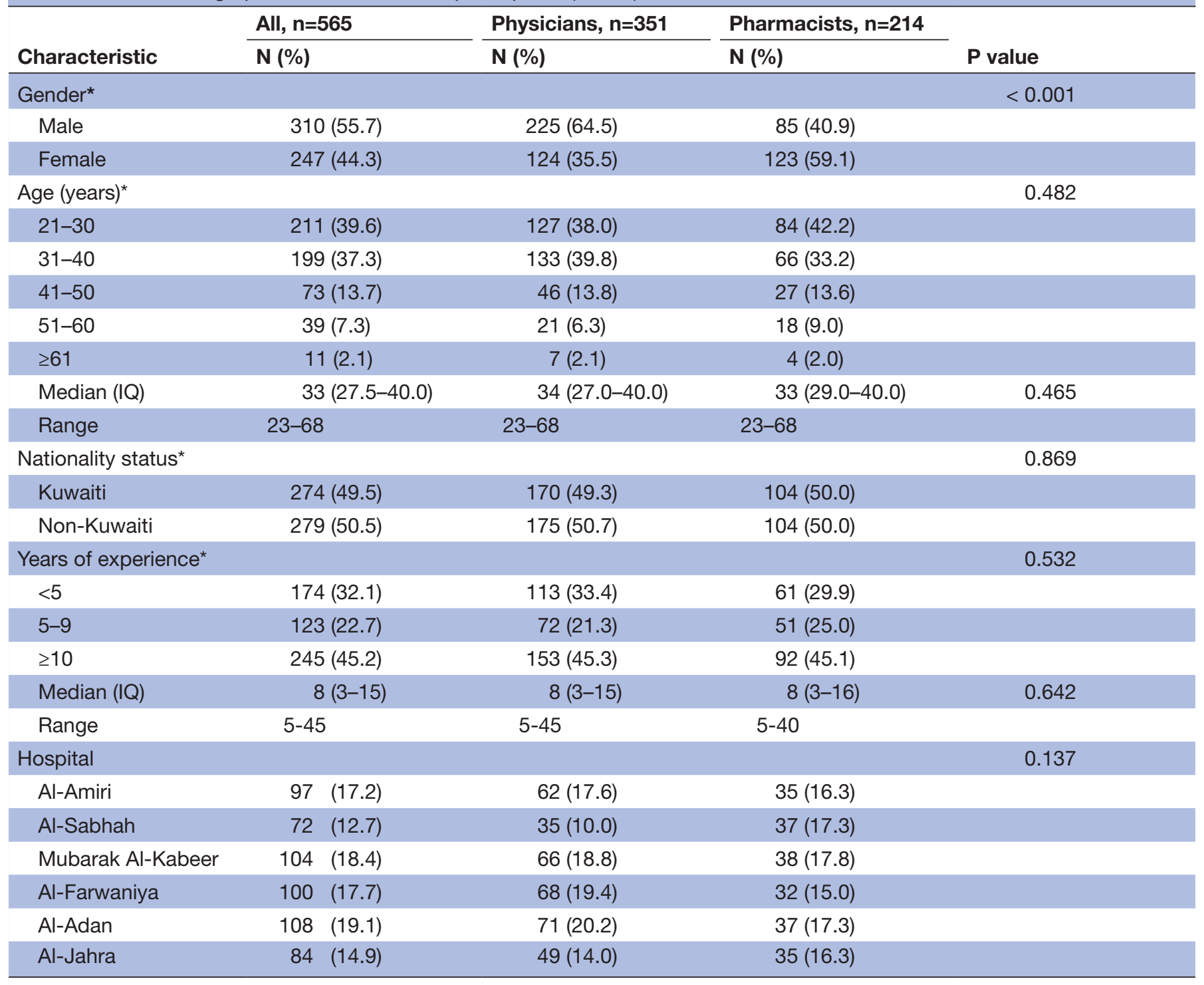

*indicates missing values.

$I Q$, interquartile.

Table 2 Knowledge and training about medication reconciliation among physicians and pharmacists working in governmental hospitals in Kuwait

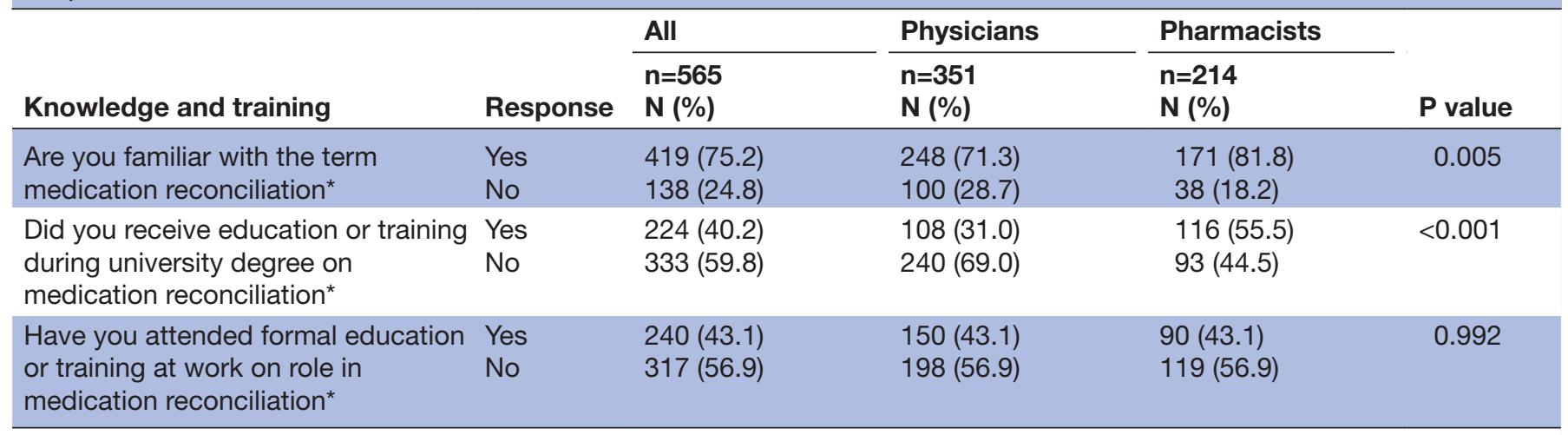

*Indicates missing values. 


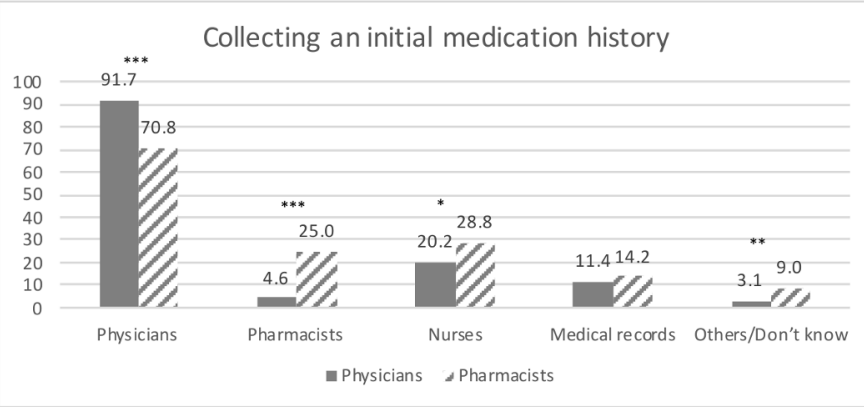

Reconciling history and admission orders
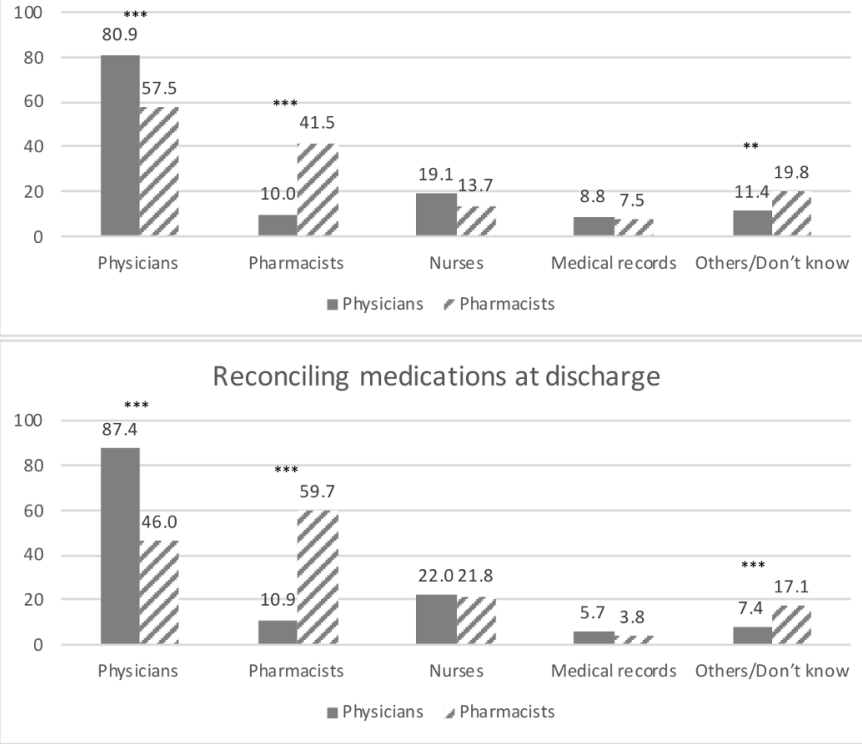

Physicians versus pharmacists; *p<0.05, **p<0.01, ***p $<0.001$

Figure 1 In your institution, who (\%) is responsible for:

were aware of policies, about one-third $(n=81 / 268$; $30.2 \%$ ) reported that MedRec should be done within 24 hours of admission, as per ISMP recommendation. However, a third of the participants $(n=86 / 268 ; 32.1 \%)$ did not know within how many hours all medications

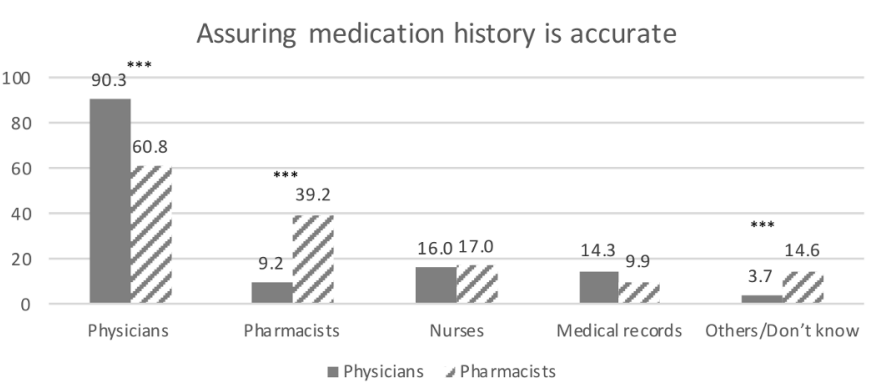

Reconciling medications upon transfer

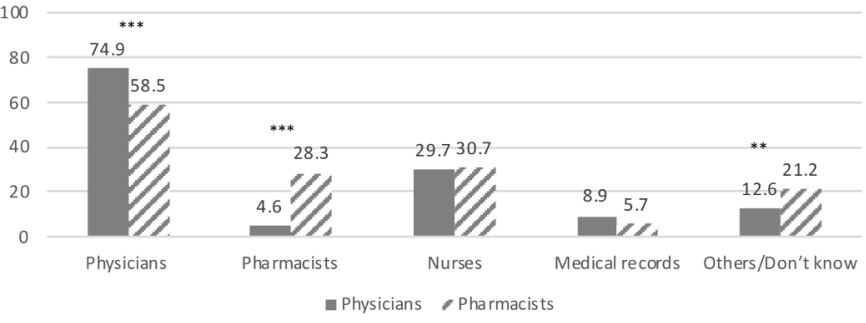

Sending patient's discharge medication list to next provider

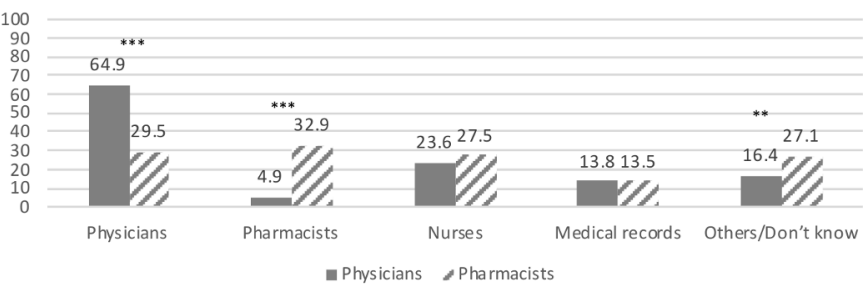

must be reconciled after patient admission, with significantly more pharmacists not knowing this information compared with physicians $(\mathrm{n}=38 / 75 ; 50.6 \%$ vs $\mathrm{n}=48 / 193$; $24.9 \% ; \mathrm{p}=0.011)$. Approximately a third of participants $(\mathrm{n}=95 / 263 ; 36.1 \%)$ were aware that their policy specified

Table 3 Participant response to medication reconciliation policy in the hospital/department

\begin{tabular}{|c|c|c|c|c|c|}
\hline & & All & Physicians & Pharmacists & \\
\hline Medication reconciliation policy & Response & $\begin{array}{l}n=565 \\
N(\%)\end{array}$ & $\begin{array}{l}n=351 \\
N(\%)\end{array}$ & $\begin{array}{l}n=214 \\
N(\%)\end{array}$ & $P$ value \\
\hline \multirow{3}{*}{$\begin{array}{l}\text { Is there a policy in the hospital on } \\
\text { medication reconciliation? }\end{array}$} & Yes & 273 (49.2) & 195 (55.9) & $78(37.9)$ & $<0.001$ \\
\hline & No & $123(22.2)$ & $48(13.8)$ & $75(36.4)$ & $<0.001$ \\
\hline & Don't Know & $159(28.6)$ & $106(30.4)$ & $53(25.7)$ & 0.237 \\
\hline \multirow{4}{*}{$\begin{array}{l}\text { If yes, after an admission mediation } \\
\text { history is obtained, does your policy } \\
\text { states within how many hours all } \\
\text { medications must be reconciled?* }\end{array}$} & 12 hours & $92(34.3)$ & 77 (39.2) & $15(20.0)$ & 0.003 \\
\hline & 24 hours & $81(30.2)$ & 64 (33.2) & $17(22.7)$ & 0.094 \\
\hline & 48 hours & $9(3.4)$ & $4(2.1)$ & $5(6.7)$ & 0.062 \\
\hline & Others/ Don't Know & $86(32.1)$ & $48(24.9)$ & $38(50.6)$ & 0.011 \\
\hline \multirow{3}{*}{$\begin{array}{l}\text { If yes, does your policy specify a } \\
\text { different timeframe for reconciliation } \\
\text { depending on critical nature of drugs on } \\
\text { the mediation history list?* }\end{array}$} & Yes & $95(36.1)$ & 63 (33.2) & $32(43.8)$ & 0.11 \\
\hline & No & $57(21.7)$ & $42(22.1)$ & $15(20.5)$ & 0.778 \\
\hline & Don’t know & $111(42.2)$ & $85(44.7)$ & $26(35.6)$ & 0.182 \\
\hline
\end{tabular}

*Indicates missing values. 
Table 4 Respondents (\%) on duration a medication reconciliation process has been in place in your department/hospital

\begin{tabular}{|c|c|c|c|c|c|c|}
\hline \multirow{2}{*}{ Duration } & \multicolumn{2}{|c|}{ For admissions } & \multicolumn{2}{|c|}{ For transfers } & \multicolumn{2}{|c|}{ For discharges } \\
\hline & $\begin{array}{l}\text { Physicians } \\
\mathrm{n}=348\end{array}$ & $\begin{array}{l}\text { Pharmacists } \\
\mathrm{n}=208\end{array}$ & $\begin{array}{l}\text { Physicians } \\
\mathrm{n}=348\end{array}$ & $\begin{array}{l}\text { Pharmacists } \\
\mathrm{n}=209\end{array}$ & $\begin{array}{l}\text { Physicians } \\
\mathrm{n}=347\end{array}$ & $\begin{array}{l}\text { Pharmacists } \\
\mathrm{n}=209\end{array}$ \\
\hline $1-6$ months & $75(21.5)^{\star}$ & $30(14.4)$ & $61(17.5)$ & $30(14.4)$ & $64(18.4)$ & 35 (16.7) \\
\hline $7-12$ months & $33(9.5)^{\star}$ & 8 (3.9) & $31(8.9)$ & $11(5.3)$ & $24(6.9)$ & $9(4.3)$ \\
\hline Don't know & $148(42.5)$ & 108 (51.9) & $174(50.0)$ & $114(54.5)$ & $155(44.7)$ & 109 (52.2) \\
\hline
\end{tabular}

${ }^{*}$ Physicians versus pharmacists; ${ }^{*} p<0.05,{ }^{* *} p<0.01,{ }^{* * *} p<0.001$.

a different timeframe (ie, number of hours by which medications must be reconciled after admission) for reconciliation depending on the critical nature of medications (ie, high alert medications such as anticoagulants, narcotics and so on) on the medication history list, whereas $21.7 \%$ $(\mathrm{n}=57 / 263)$ were not aware and $42.2 \%(\mathrm{n}=111 / 263)$ did not know. No significant difference was noticed between pharmacists and physicians.

Participants were asked how long they believed a MedRec process had been in place in their institution. Interestingly, about half of them did not know of such processes either for admission $(\mathrm{n}=256 / 556 ; 46.0 \%)$, transfer $(\mathrm{n}=288 / 557 ; 51.7 \%)$ or discharge $(\mathrm{n}=264 / 556$; $47.5 \%$ ), with no significant difference between physicians and pharmacists (table 4). About $10 \%$ of participants reported that there was no process in place, with significantly more pharmacists believing so, compared with physicians, for admissions $(\mathrm{n}=36 / 208 ; 17.3 \%$ vs $\mathrm{n}=26 / 348 ; 7.5 \%, \mathrm{p}<0.001)$, transfers $(\mathrm{n}=36 / 209 ; 17.2 \%$ vs $\mathrm{n}=31 / 348 ; 8.9 \%, \mathrm{p}<0.01)$ and discharge, $(\mathrm{n}=35 / 209$; $16.8 \%$ vs $\mathrm{n}=21 / 347 ; 6.1 \%, \mathrm{p}<0.001)$.

\section{MedRec practices}

Most participants ( $\mathrm{n}=468 / 562 ; 83.3 \%)$ reported asking patients for a current list of medication on arrival in their service, significantly more physicians compared with pharmacists $(\mathrm{n}=339 / 351 ; 96.6 \%$ vs $\mathrm{n}=129 / 211 ; 61.1 \%$; $\mathrm{p}<0.001$ ) (table 5). Interestingly, significantly more pharmacists rarely or never asked patients for a current list of medication ( $\mathrm{n}=82 / 211 ; 38.9 \%$ vs $\mathrm{n}=12 / 351 ; 3.4 \%$; $\mathrm{p}<0.001)$. About one-fifth of participants $(\mathrm{n}=97 / 557$; $17.4 \%)$, significantly more pharmacists than physicians $(\mathrm{n}=64 / 207 ; 30.9 \%$ vs $\mathrm{n}=33 / 350 ; 9.4 \% ; \mathrm{p}<0.001)$, reported that fewer than $<10 \%$ of patients arrived in their service with a current medication list (table 5). In contrast, more physicians reported that over half of their patients bring their list $(\mathrm{n}=109 / 350 ; 31.1 \%$ vs $\mathrm{n}=44 / 207 ; 21.3 \%$; $\mathrm{p}=0.012$ ) (table 5). Most participants reported not having $(\mathrm{n}=363 / 555 ; 65.4 \%)$ or not knowing $(\mathrm{n}=113 / 555 ; 20.4 \%)$ if their service has electronic connectivity with other institutions in order to obtain a medication listing for their patients. There was no significant difference between physicians and pharmacists.
Most participants indicated that the MedRec process was documented on paper and/or computer charts $(\mathrm{n}=406 / 558 ; 72.7 \%)$ (table 5). However, significantly more pharmacists reported that the process was not documented $(\mathrm{n}=31 / 207 ; 15.0 \%$ vs $\mathrm{n}=9 / 351 ; 2.6 \%$; $\mathrm{p}<0.001)$ or not knowing if it was documented $(\mathrm{n}=51 / 207 ; 24.6 \%$ vs $\mathrm{n}=61 / 351 ; 17.4 \% ; \mathrm{p}<0.012)$. Significantly more physicians compared with pharmacists indicated that the prescribers order medications on the same form/screen used to document the initial medication history $(n=123 / 348 ; 35.3 \%$ vs $\mathrm{n}=48 / 208 ; 23.1 \% ; \mathrm{p}=0.003$ ) and interestingly $29.9 \%$ ( $\mathrm{n}=166 / 556)$ of participants reported not knowing.

About half of participants $(n=271 / 559 ; 48.5 \%)$, with significantly more pharmacists than physicians $(\mathrm{n}=122 / 211 ; \quad 57.8 \% \quad$ vs $=149 / 348 ; \quad 42.8 \% ; \quad \mathrm{p}<0.001)$ reported that their computer system can print a list of current medications. More than half of them $(n=334 / 553$; $60.4 \%$ ) indicated that the computer-generated medication list includes detailed information, such as dose, route, frequency and duration of treatment. Significantly more physicians reported routinely providing a current list to their patients $(\mathrm{n}=281 / 351 ; 80.1 \%$ vs $\mathrm{n}=107 / 207$; $52.0 \%$; $\mathrm{p}<0.001$ ) (table 5).

With an open-ended question, additional comments and suggestions were provided by a few $(n=12 / 565$; $2.1 \%$ ) participants (physicians: $5 / 351 ; 1.4 \%$ and pharmacists: $n=6 / 214 ; 2.8 \%$ ). These included that the MedRec process should involve patients $(n=1)$, be done collaboratively between physicians and pharmacists $(n=3)$, be implemented in every hospital's information system with common electronic forms and be centrally computerised $(n=6)$. Other comments included the need for practical hands-on training $(\mathrm{n}=1)$ and formal policies to implement MedRec $(\mathrm{n}=1)$.

\section{DISCUSSION}

In the context of patient safety initiatives and in-line with international accreditation standards, the $\mathrm{MoH}$ is investing significant efforts in meeting these standards and obtaining accreditation for its healthcare institutions. MedRec is an important accreditation requirement, and 
Table 5 Practices involved in the medication reconciliation process among physicians and pharmacists working in government hospitals in Kuwait $(n=565)$

\begin{tabular}{|c|c|c|c|c|c|}
\hline Practices/documentation & Response & $\begin{array}{l}\text { All } \\
n=565 \\
N(\%)\end{array}$ & $\begin{array}{l}\text { Physicians } \\
\mathrm{n}=351 \\
\mathrm{~N}(\%)\end{array}$ & $\begin{array}{l}\text { Pharmacists } \\
\mathrm{n}=214 \\
\mathrm{~N}(\%)\end{array}$ & $P$ value \\
\hline \multicolumn{6}{|l|}{ Best possible medication history practices: } \\
\hline \multirow{2}{*}{$\begin{array}{l}\text { Do you routinely ask patients for a current } \\
\text { list of medications when they arrive in your } \\
\text { service? }{ }^{*}\end{array}$} & Yes & $468(83.3)$ & $339(96.6)$ & $129(61.1)$ & $<0.001$ \\
\hline & Rarely/never & $94(16.7)$ & $12(3.4)$ & $82(38.9)$ & \\
\hline \multirow{4}{*}{$\begin{array}{l}\text { What percentage of patients has a current } \\
\text { and complete list of their medications when } \\
\text { they arrive in your service? }\end{array}$} & $<10 \%$ & $97(17.4)$ & $33(9.4)$ & $64(30.9)$ & $<0.001$ \\
\hline & $10 \%-30 \%$ & $162(29.1)$ & $108(30.8)$ & $54(26.1)$ & 0.238 \\
\hline & $30 \%-50 \%$ & $145(26.0)$ & $100(28.6)$ & $45(21.7)$ & 0.073 \\
\hline & $>50 \%$ & $153(27.5)$ & 109 (31.1) & $44(21.3)$ & 0.012 \\
\hline \multicolumn{6}{|l|}{ Documentation: } \\
\hline \multirow{3}{*}{$\begin{array}{l}\text { On which type of form is your medication } \\
\text { reconciliation process is documented?* }\end{array}$} & Charts & $406(72.7)$ & $281(80.0)$ & $125(60.4)$ & $<0.001$ \\
\hline & None & $40(7.2)$ & $9(2.6)$ & $31(15.0)$ & $<0.001$ \\
\hline & Don’t know & $112(20.1)$ & $61(17.4)$ & $51(24.6)$ & 0.012 \\
\hline \multirow{4}{*}{$\begin{array}{l}\text { Does the prescriber order medications } \\
\text { directly on the same form or screen used to } \\
\text { document the initial medication history?*}\end{array}$} & Yes & $171(30.8)$ & $123(35.3)$ & $48(23.1)$ & 0.003 \\
\hline & No & $113(20.3)$ & $58(16.7)$ & $55(26.4)$ & 0.006 \\
\hline & Sometimes & $106(19.0)$ & $59(17.0)$ & $47(22.6)$ & 0.104 \\
\hline & Don’t know & 166 (29.9) & $108(31.0)$ & $58(27.9)$ & 0.44 \\
\hline \multicolumn{6}{|l|}{ Medication lists: } \\
\hline \multirow{3}{*}{$\begin{array}{l}\text { Is your computer system capable of printing } \\
\text { a list of current prescription medication for } \\
\text { patients on demand?* }\end{array}$} & Yes & $271(48.5)$ & $149(42.8)$ & $122(57.8)$ & $<0.001$ \\
\hline & No & $228(40.8)$ & $151(43.4)$ & 77 (36.5) & 0.089 \\
\hline & Don't know & $60(10.7)$ & $48(13.8)$ & $12(5.7)$ & 0.003 \\
\hline \multirow{2}{*}{$\begin{array}{l}\text { Does the computer-generated medication } \\
\text { list provided to patients include dose, route, } \\
\text { frequency, duration of treatment and time of } \\
\text { last refill (if applicable) for each medication } \\
\text { listed?* }\end{array}$} & Yes & $334(60.4)$ & $210(60.7)$ & 124 (59.9) & 0.853 \\
\hline & No/NA & 219 (39.6) & 136 (39.3) & $83(40.1)$ & \\
\hline \multirow{2}{*}{$\begin{array}{l}\text { Do you routinely provide a list of current } \\
\text { medications to patients?* }\end{array}$} & Yes & $388(69.7)$ & $281(80.1)$ & $107(52.0)$ & $<0.001$ \\
\hline & No & $169(30.3)$ & 70 (19.9) & $99(48.0)$ & \\
\hline
\end{tabular}

*Indicates missing values.

this study provides data on the current state of MedRec in Kuwait and suggests ways to further implement MedRec in governmental hospitals. In line with data from Oman and Jordan, ${ }^{11}{ }^{13}$ our findings indicate that the majority of participants were familiar with MedRec and perceived it as a highly valuable process. These observations were expected given the fact that $\mathrm{MoH}$ hospitals are seeking accreditation and MedRec is a ROP, and as such, the quality and accreditation departments have raised awareness and discussed MedRec in the workplace. Overall, participants in this study perceived that physicians were the main healthcare professionals responsible for the various steps of the MedRec process, which is in line with recent findings. ${ }^{11} 1416$ These studies showed that physicians, nurses and pharmacists had different perspectives regarding MedRec and were not clear on which profession was responsible for various steps of the process. In Kuwait, these perceptions may be driven by the policies that hold physicians solely responsible for the entire process and do not clearly define each step of the process, including task delegation involving other healthcare professionals in the process workflow, that is, collecting and documenting BPMH, reconciling BPMH to in-hos$\mathrm{pital} /$ discharge medication orders. ${ }^{21}$ Currently, the expertise of inpatient pharmacists is not optimised as their role is mainly limited to technical work in the dispensary. In this context, it may prove valuable to revise the current policies and procedures to align them with international standards and ISMP guidelines ${ }^{2}$ and to develop workflows for points of transition in care to clearly define roles and responsibilities, reallocate tasks and responsibilities, standardise the MedRec process and promote collaboration among HCP, with MedRec being a shared responsibility. The MedRec training received at workplace may have also contributed to familiarity and basic understanding of the MedRec process and its value. Yet, our findings suggest a 
lack of thorough understanding of the orchestrated roles and responsibilities of each HCP involved in the MedRec process. Even if more pharmacists were taught MedRec at university, additional training, namely for BPMH, both in university and workplace, would be beneficial.

The present study assessed the awareness of participants about the availability of a MedRec policy at their institution. Surprisingly, and despite the fact that the $\mathrm{MoH}$ hospitals are in the process of implementing MedRec as a ROP by Accreditation Canada International, our results showed that almost half of the participants were aware about the presence of a MedRec policy; however, that awareness was significantly lower among pharmacists as compared with physicians. This is consistent with similar results reported in Jordan, which have demonstrated low awareness among pharmacists concerning the presence of a MedRec policy at their healthcare institutions. ${ }^{13}$ Similarly, there was low awareness when participants were specifically asked for how long they believed a MedRec process had been in place at their institution as well as the time frame required for reconciling medications on admission. These findings could be explained by the fact that there was insufficient knowledge dissemination about the ROP policy and procedures to HCP and more specifically to pharmacists, although a MedRec policy was issued in January 2016 by the MoH Quality and Accreditation Directorate and circulated to its individual healthcare institutions. ${ }^{21}$ Furthermore, the fact that treating physicians are considered as solely responsible for the MedRec process as highlighted in the policy clearly explains higher awareness among physicians.

MedRec is a shared responsibility and a patient-centred process. ${ }^{22}$ In the present study, and as compared with physicians, a significantly larger proportion of pharmacists rarely or ever asked patients for their current list of medications to verify their medications on admission to a medical service. This might in part be related to the pharmacist's current practice setting, presence in the wards, job description or lack of clarity about systematic approach involved in obtaining a BPMH and standards of MedRec practice. This finding may also be due to the fact that physicians are the HCPs assigned with the responsibility of collecting and documenting BPMH as per the national $\mathrm{MoH}$ policy, thus excluding pharmacists from such a practice. The policy only includes a general statement indicating that pharmacists may participate in the process along with nurses as far as they receive the needed knowledge, skills and behaviour to perform this function; yet, not a single role is assigned to them throughout the whole process. ${ }^{21}$ This contrasts the concept of an interprofessional MedRec process designed to ensure optimal medication management. ${ }^{1022}$ Published literature clearly supports the role of pharmacists as an integral part in the process and that their involvement in collecting and documenting a complete and accurate BPMH has positively impacted patients' health outcomes and prevented adverse drug events due to identified discrepancies at interfaces of care. ${ }^{93}$ In fact, pharmacists believe that they have the skills required to lead this process but their current role in providing clinical services in Kuwait, including MedRec, is limited and mainly revolves around education, drug information, technical and drug distribution duties. ${ }^{24}$ Pharmacists should have a significant involvement in the MedRec process, namely by collecting the BPMH. Then, physicians could review the medications list to make a conscientious decision of what to continue, modify or discontinue at the points of transition in care.

Physicians reported that over half of their patients bring their list of medications with them. In contrast, Horn et $a l^{18}$ reported a lack of patient involvement in providing a list of current medications at the time of patient visit to emergency departments and community pharmacies. ${ }^{18}$ This may be due to a difference in the type of healthcare setting and pace of medical service visited by patients, specifically emergency departments, as well as lack of patient's awareness. Patient's involvement in the process and their knowledge about their medications is essential to ensure safe medication practices during transition in care. To increase patients' awareness and improve communication about their medications with HCPs, an education-based initiative ' 5 questions to ask about your medications' was developed and launched by ISMP in collaboration with multiple Canadian organisations and could be adapted for $\mathrm{MoH}$ hospitals in Kuwait. Multiple hospitals across Canada had endorsed and adapted this initiative with the support of ISMP. ${ }^{25}$

Participants reported that there are two approaches to document the BPMH/MedRec process in the public hospitals in Kuwait: paper and electronic records base. However, significantly more pharmacists reported that the process was not documented. This may be due to lack of knowledge about the documentation process since they are not actively involved or assigned any role in it. In addition, most participants reported that there was no interinstitutional connectivity or that they did not know about its presence to assist them in obtaining a medications list for the patients to help with the BPMH step of the process. These findings highlight a major caveat that is present in the current medication management workflow that needs to be optimised and addressed as soon as possible. Pharmacists should have access to all patient medication information and should know where to document and/or where to locate such information, even when performing their technical dispensing role in order to ensure safe medication practices. Data from the literature support computerisation in aiding the MedRec process. Studies showed that implementation of MedRec electronically led to better understanding by the patients of their discharge medications and minimised medication discrepancies such as omissions, commissions, wrong dose or frequency, duplications or wrong drug selection that might occur during admission, transfer and discharge and may lead to potential adverse events. ${ }^{26}{ }^{27}$ However, this may be limited by how user-friendly the software is and how well trained the users of the interface are. At this time, there is no centralised connectivity, and there is no common health 
information system to collect and document patient medication histories. This will require intervention of the $\mathrm{MoH}$ to standardise interinstitutional connectivity, drug databases and medication order entries. In fact, the technology is available to provide patients with a list to carry with them when moving between healthcare systems, but yet is not optimally used or centrally connected to offer physicians and pharmacists an optimised information exchange when patients move from one healthcare setting to another. More pharmacists reported that their computer system can generate and print a current patient medication list with the required detailed information, but more physicians routinely provide the list to their patients. This may be due to the fact that physicians are the only HCPs assigned a role in the MedRec process; they are the ones making final decision about medication changes for their patients during the patient's visit to their medical service. Interprofessional collaboration and delegation of the counselling service to pharmacists should be encouraged allowing both physicians and pharmacists to optimise their role and scope of practice. Furthermore, pharmacists may not have received any requests or asked to provide a list, may not be aware of the value due to lack of knowledge about the concept or may not have access or authorisation to print and give the list to patients.

MedRec is not simply a nominal process; instead, it requires a rigorous and efficient strategy to ensure appropriate knowledge dissemination, effective training and process implementation. ${ }^{28}$ Therefore, standardised education programmes are urgently needed, should be delivered by experienced personnel across all public hospitals and enforced by the MoH Quality and Accreditation Directorate. Furthermore, reallocating tasks and responsibilities to other regulated healthcare professionals besides physicians in the $\mathrm{MoH}$ policy may be the most critically needed change in the implementation process.

\section{CONCLUSION}

Overall and in line with international accreditation standards, this study showed that MedRec initiatives have started in Kuwait governmental hospitals and are perceived as a valuable patient safety initiative. Providing onsite training on the MedRec process and its policies and optimising current technologies to draw additional value from the existing computerised systems would provide value to HCPs and support $\mathrm{MoH}$ in its accreditation objectives. Recommendations to improve the existing MedRec process based on the ISMP guidelines would include involving other HCPs in the process and revising the policies accordingly. This must be supported by continuous onsite training on the policy, procedures and workflows and on BPMH, which is the cornerstone of MedRec. In the near future, it would be worthwhile to measure and document with more details the practices in every step of the MedRec process in order to enhance and streamline the current practices.
Acknowledgements The technical contribution of Fatima Al-Mutawa is gratefully acknowledged.

Contributors JL designed the study and adapted the study tool; she analysed and interpreted the data and drafted and revised the paper. She is the guarantor. TB contributed significantly to the study design and tool, interpretation and discussion of the results and revised the paper. $\mathrm{HH}$ collected a significant portion of the data, contributed to drafting part of the paper and revised the paper. PS conducted additional data analysis and verified all the results and revised the draft paper.

Funding This research received no specific grant from any funding agency in the public, commercial or not-for-profit sectors.

Disclaimer The present paper represents the opinions of the authors and does not necessarily reflect the position of their employers.

Competing interests None declared.

Patient consent for publication Not required.

Ethics approval Ethical approval was obtained from the Standing Committee for Coordination of Health and Medical Research, $\mathrm{MoH}$ and the Health Sciences Center (HSC) Ethics Committee for Student Research.

Provenance and peer review Not commissioned; externally peer reviewed.

Data sharing statement № additional data are available.

Open access This is an open access article distributed in accordance with the Creative Commons Attribution Non Commercial (CC BY-NC 4.0) license, which permits others to distribute, remix, adapt, build upon this work non-commercially, and license their derivative works on different terms, provided the original work is properly cited, appropriate credit is given, any changes made indicated, and the use is non-commercial. See: http://creativecommons.org/licenses/by-nc/4.0/.

\section{REFERENCES}

1. IHI. http://www.ihi.org/ (accessed mar 2019).

2. ISMP. https://www.ismp.org/ (accessed mar 2019).

3. The Joint Commission. https://www.jointcommission.org/ (accessed Mar 2019).

4. Tam VC, Knowles SR, Cornish PL, et al. Frequency, type and clinical importance of medication history errors at admission to hospital: a systematic review. CMAJ 2005;173:510-5.

5. Lehnbom EC, Stewart MJ, Manias E, et al. Impact of medication reconciliation and review on clinical outcomes. Ann Pharmacother 2014;48:1298-312.

6. Mendes AE, Lombardi NF, Andrzejevski VS, et al. Medication reconciliation at patient admission: a randomized controlled trial. Pharm Pract 2016;14:656.

7. Michaelsen $\mathrm{MH}, \mathrm{McC}$ ague $\mathrm{P}$, Bradley $\mathrm{CP}$, et al. Medication Reconciliation at Discharge from Hospital: A Systematic Review of the Quantitative Literature. Pharmacy 2015;3:53-71.

8. Pronovost $\mathrm{P}$, Weast $\mathrm{B}$, Schwarz $\mathrm{M}$, et al. Medication reconciliation: a practical tool to reduce the risk of medication errors. $J$ Crit Care 2003;18:201-5.

9. Smith L, Mosley J, Lott S, et al. Impact of pharmacy-led medication reconciliation on medication errors during transition in the hospital setting. Pharm Pract 2015;13:634.

10. Varkey P, Cunningham J, O'Meara J, et al. Multidisciplinary approach to inpatient medication reconciliation in an academic setting. Am J Health Syst Pharm 2007;64:850-4.

11. Al-Hashar A, Al-Zakwani I, Eriksson T, et al. Whose responsibility is medication reconciliation: Physicians, pharmacists or nurses? A survey in an academic tertiary care hospital. Saudi Pharm J 2017;25:52-8.

12. Boockvar KS, Santos SL, Kushniruk A, et al. Medication reconciliation: barriers and facilitators from the perspectives of resident physicians and pharmacists. J Hosp Med 2011;6:329-37.

13. Hammour KA, Farha RA, Basheti I. Hospital pharmacy medication reconciliation practice in Jordan: perceptions and barriers. J Eval Clin Pract 2016;22:936-41.

14. Lee KP, Hartridge $C$, Corbett $K$, et al. "Whose job is it, really?" Physicians', nurses', and pharmacists' perspectives on completing inpatient medication reconciliation. J Hosp Med 2015;10:184-6.

15. van Sluisveld N, Zegers M, Natsch S, et al. Medication reconciliation at hospital admission and discharge: insufficient knowledge, unclear task reallocation and lack of collaboration as major barriers to medication safety. BMC Health Serv Res 2012;12:170.

16. Vogelsmeier A, Pepper GA, Oderda L, et al. Medication reconciliation: A qualitative analysis of clinicians' perceptions. Res Social Adm Pharm 2013;9:419-30. 
17. Clay BJ, Halasyamani L, Stucky ER, et al. Results of a medication reconciliation survey from the 2006 Society of Hospital Medicine national meeting. J Hosp Med 2008;3:465-72.

18. Horn D, Gaunt MJ, Vaida AJ. Medication Reconciliation: A Survey of Community Pharmacies and Emergency Departments. Patient Safety and Quality in Healthcare 2010 https://www.psqh.com/analysis/ medication-reconciliation-a-survey-of-community-pharmacies-andemergency-departments/ (accessed mar 2019).

19. ISMP. Practitioners Agree on Medication Reconciliation Value. But Frustration and Difficulties Abound 2006 https://www.ismp.org/ resources/practitioners-agree-medication-reconciliation-valuefrustration-and-difficulties-abound (accessed Nov 2017).

20. Raosoft I. Raosoft Sample Size Calculator. 2004.

21. Ministry of Health Quality and Accreditation Directorate. Medication reconcil-iation policy. Kuwait: $\mathrm{MOH}, 2009$.

22. Greenwald JL, Halasyamani L, Greene J, et al. Medication Reconciliation: A Consensus Statement From Stakeholders. J Hosp Med 2010;8:477-85.
23. Nester TM, Hale LS. Effectiveness of a pharmacist-acquired medication history in promoting patient safety. Am J Health Syst Pharm 2002;59:2221-5.

24. Lemay J, Waheedi M, Al-Taweel D, et al. Clinical pharmacy in Kuwait: Services provided, perceptions and barriers. Saudi Pharm J 2018;26:481-6.

25. ISMP Canada. 5 Questions to Ask About Your Medications. https:// www.ismp-canada.org/medrec/5questions.htm (accessed march 2019).

26. Kramer JS, Hopkins PJ, Rosendale JC, et al. Implementation of an electronic system for medication reconciliation. American Journal of Health-System Pharmacy 2007;64:404-22.

27. Schnipper JL, Hamann C, Ndumele CD, et al. Effect of an electronic medication reconciliation application and process redesign on potential adverse drug events: a cluster-randomized trial. Arch Intern Med 2009;169:771-80.

28. Fernandes O. Medication reconciliation in the hospital: what, why, where, when, who and how? Healthc Q 2012;15:42-9. 